\title{
EVALUATION OF THE LEVEL OF WORK SAFETY, ADVANCEMENT AND EFFICIENCY OF THE USE OF MACHINES AND DEVICES ON LABELLING AND PACKAGING LINE AND AN ATTEMPT TO COMPARE THE RESULTS USING THE MODIFIED MCKINSEY MATRIX
}

doi: $\quad 10.2478 /$ czoto-2019-0024

Date of submission of the article to the Editor: 05/11/2018

Date of acceptance of the article by the Editor: 30/12/2018

\author{
Krzysztof Knop ${ }^{1}$ - orcid id: 0000-0003-0842-9584 \\ Pavlína Mikulová ${ }^{2}$ - orcid id: 0000-0002-2035-029X \\ ${ }^{1}$ Czestochowa University of Technology, Poland, krzysztof.knop@wz.pcz.pl \\ ${ }^{2}$ Technical University of Ostrava, Czech Republic
}

\begin{abstract}
The article presents the results of the assessment of the level of work safety, the level of modernity and the efficiency of the use of machines on the labelling and packaging line. The assessment of the level of occupational safety was made on the basis of an interview conducted with machine operators, by direct observation and analysis of historical data. The basis for assessing the level of modernity was the ABC technology method and the 5-stage Parker scale, while the OEE indicator was used to assess the level of efficiency of the use. An assessment of the level of safety, modernity, efficiency and other aspects such as cleanliness, completeness, maintenance, improvements for machines in the line with the use a scale of 0-5 was included and next, based on the validity index, the overall result was calculated. Modified McKinsey matrix was used to evaluate these factors and comparison the obtained results with other lines in the company. As a result of the conducted analyzes, it was pointed out that it is necessary to take improvement measures in the area of the worst-assessed factors.
\end{abstract}

Keywords: safety, advancement, efficiency, McKinsey matrix, labelling and packaging line

\section{INTRODUCTION}

The labelling and packaging process is the last of the processes of confectioning a food product. These procedures require special care due to their great impact on the final aesthetics of the food product, which affects the first impression that the product leaves in the customers' eyes. Due to the fact that they often "shop with their eyes", such factors as aesthetics, correct marking, proper product security during transport may affect whether the customer (wholesaler, consumer) decides to purchase a given 
food product (or batch of a food product) (Yam et. al, 2005). High requirements as to the aesthetics of the final product cause the labelling and packaging processes to become operations requiring ever greater precision and quality. A label has got not only an information function today, but it is also a marketing tool (Knop and Borkowski, 2009). Its effectiveness is determined not just by an adequate graphic design or shape adapted to a particular packaging, but also by the durability and precision of its sticking method (Kula, 2004).

The quality of every process is influenced by many factors $(7 M+E)$, which should be measured (Mikulová and Plura, 2018), analysed and improvement (Ulewicz, 2016), among which it should be distinguished factors such as the level of advancement of machines, the level of efficiency of machine usage, qualifications and competences of operators and maintenance staff (which determine the correct setting, operation of machines). Indirect factor also includes the level of occupational safety. The quality of the operator work and indirectly the quality of the device work depend on the extent, which the employees feel safe in a given area of work to (Maszke et al., 2018; Krynke and Mielczarek, 2018).

The aim of the undertaken research work was to relate the results in the field of advancement evaluation and machine work efficiency as well as the level of work safety on the labelling and packaging line for a food product (tomato paste) with a purpose of a comprehensive assessment of the analysed machines and lines. The results in this respect were employed for a comparative analysis and for initiation of activities improving the quality of the labelling and packaging process as well as the efficiency of the use of machines on the analysed line.

\section{METHODOLOGY OF RESEARCH}

Advancement of machines, efficiency of their usage, work safety and quality are factors dependent on each other. In order to determine the type of this dependence and their direction (from the cause to the effect) a new quality tool (Dziuba et al., 2016) was used - a relation diagram. The result of the analysis of the interdependencies between these factors is presented in the Fig. 1.

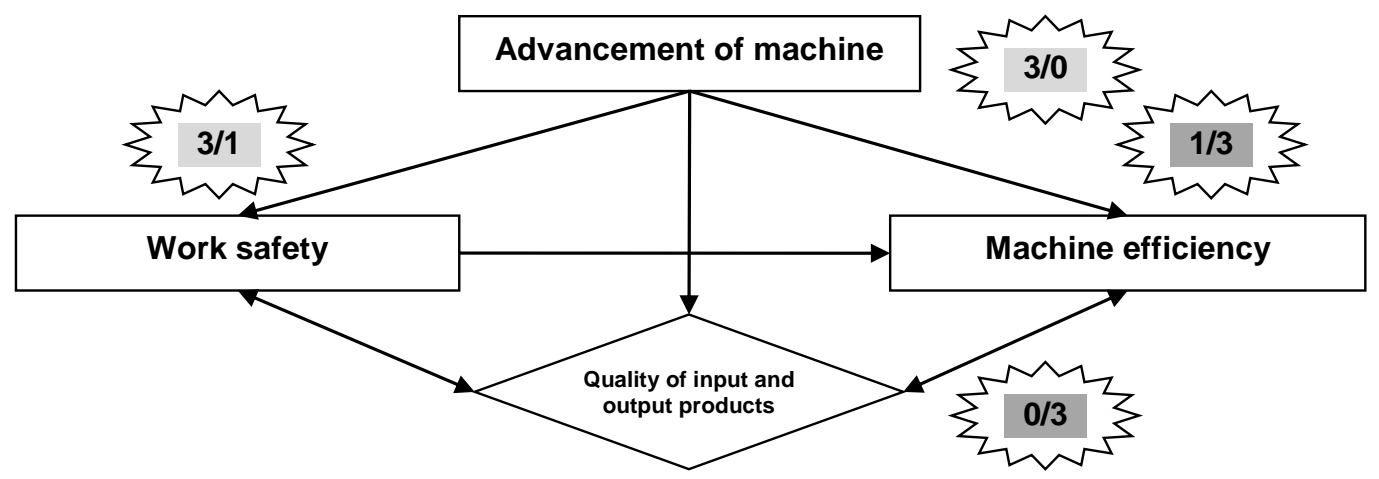

Fig. 1. The result of the analysis of the cause-effect relationship between four factors as the starting point for the research.

Source: Own study

The presented analysis prove that the key causal factor is machine advancement and work safety, while the key resultant (effect) factor is the product quality and efficiency of machine usage. In order to improve the quality of the product and the efficiency of 
the use of machinery, it is necessary to start with the activities in the area of improving work safety and advancement of the machines. This observation was the starting point for undertaking research in the field of analysis and evaluation of such factors as: advancement, efficiency and safety in relation to machines on the labelling and packaging line for comparison purposes.

The subject of the research is the labelling and packaging line employed for confectioning of food products such as tomato pastes and purees (products packed in jars) in one of the food industry companies located in the northern part of the Silesian Voivodship. The view on the tested machines in the analysed line is shown in Fig. 2.

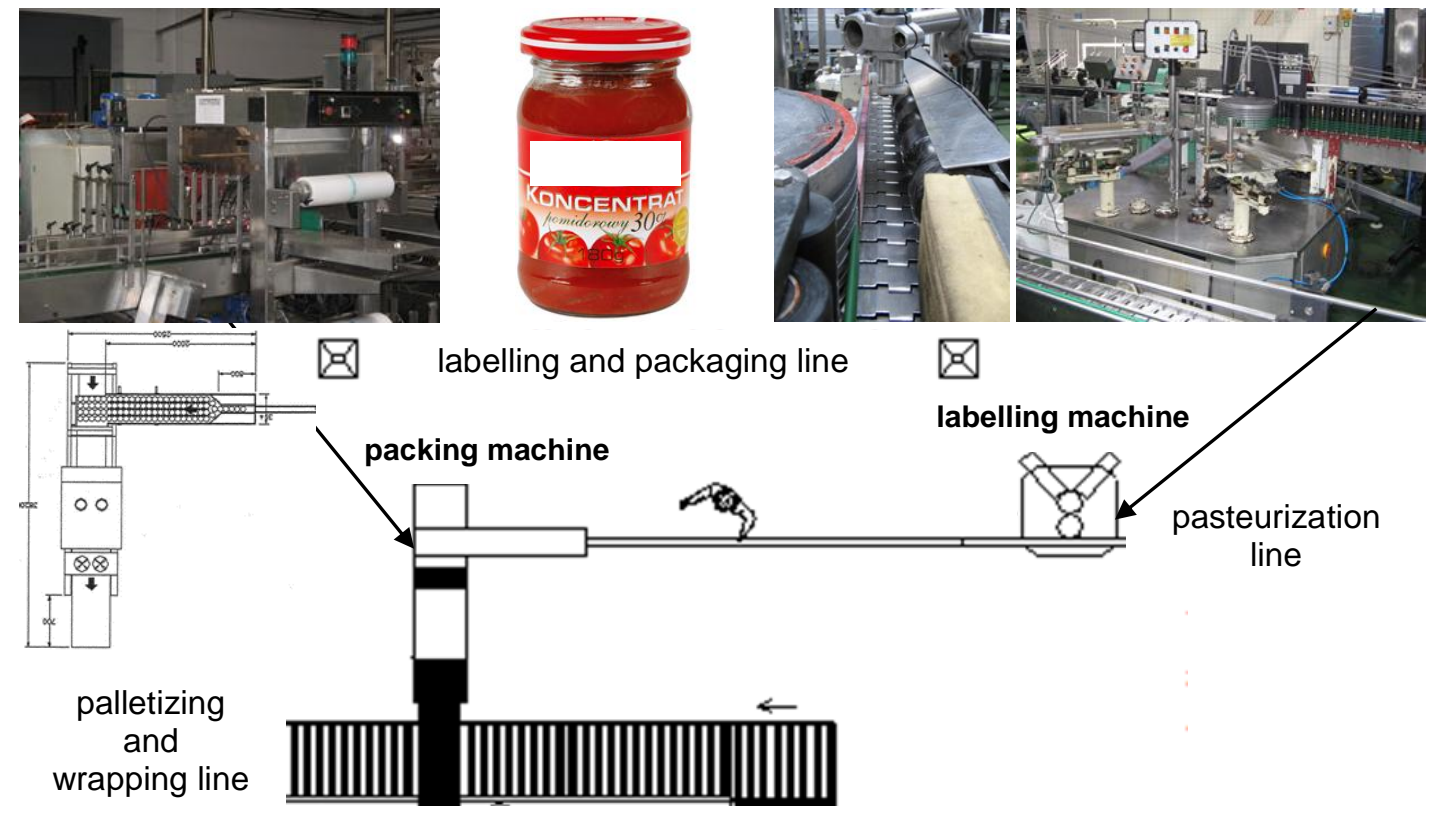

Fig. 2. Object of the research - machines on the labelling and packaging line. Source: Company's material

The first of the machines in the tested line is the Alfa Quattro labelling machine (type: Alfa Junior to 200), manufactured in Italy in 1988, intended for sticking labels on cylindrical packagings e.g.: bottles, cans or plastic packagings in the amount of 1 label per 1 packet. The labelling machine works with paper labels. The nominal capacity of the device is 12,000 packages $/ \mathrm{h}$. Another tested machine is the Packmann packing machine (type 60ASS30) of manufactured in Poland in 2004. The 60ASS30 machine is an automatic device for grouping a wide range of products and wrapping them in heat-shrinkable film.

Methodology for assessing the level of advancement of machines

The assumption was made that the assessment of each of the studied factors, such as advancement, efficiency of machines and safety level, will be carried out with the same scale of 1-5 for standardization purposes. The evaluation of the level of advancement of the tested machines was carried out using the ABC technology method and the 5-point Parker scale, the assumptions of which are widely presented in the literature (Borkowski et al., 2016). The ABC technology method allows to assess the value and usefulness of machinery and equipment for a company in a given period and gives the opportunity to evaluate and rank the advancement of 
machine components in terms of the purposefulness of their development and investment. The structure of the machine components advancement in the ABC method was presented on the basis of the Pareto-Lorenzo diagram, which provided information on the dominant level of advancement of the machines under study (Ingaldi and Dziuba, 2015). Due to the fact that the Parker scale is employed to evaluate the level of technology in the $A B C$ method, which is an order scale of $1-5$, it was used directly to assess this level.

Methodology for evaluating the level of machine usage efficiency

When evaluating the effectiveness of the use of the tested machines in the mentioned line, the OEE index was adopted, which is an indicator of the resulting production efficiency taking into account aspects such as availability $(A)$, performance $(P)$ and quality $(Q)$ of the machine's operation (Anand and Nandurkar, 2016). The OEE was calculated according to the standard formula (Muchiri and Pintelon, 2008). When calculating the OEE indicator for the line, the approach was undertaken assuming to make the calculation for the last machine in the line (i.e. for the packaging machine), due to the fact that this approach is less labor-intensive and provides a relatively accurate result (Knop, 2018). Last 30 days of the machine/line operation were assumed as the calculation period. In order to include the value of the OEE index on a scale of $1-5$, the value of the OEE index was divided in the scope of this scale, where: "1" - <35-55\%), "2" - <55-65\%), "3" - <65-75\%), "4" - <75-85\%), 5 - <85-100\%).

Methodology for evaluating the level of safety

A direct interview with machine operators, a technique for observing the work of machine operators on the spot and an analysis of historical data regarding incidents and near misses were adopted to evaluate the level of work safety. Based on the conducted analyses and observations, the occupational safety level was evaluated against the 1-5 scale, where the lowest level of occupational safety was determined by 1 , and the highest by 5 (i.e. no incidents or near misses, very strong sense of security experienced by operators when it comes to work at a given position).

Methodology of the summary assessment

In order to summarize the tested machines in the line (and at the same time the entire line itself) a modified McKinsey matrix was employed. The matrix is used to assess the level of work safety, advancement and line efficiency. Having included the experts' comments, the evaluation model was also provided with such factors as: cleanliness, completeness, maintenance, improvements, as regards their potential usefulness in the improvement process. These factors also have a mutual correlation with the quality of the (input and output) food product. Arbitrary weights (validity coefficients) were set for each factor, defining the percentage significance of each factor from the perspective of their impact on quality. The factors were evaluated using a scale of $0-5$, where the higher the score, the better the factor was assessed (the value of 0 on the scale is adopted when a given factor does not exist and is related to the improvements), and the general indicator value was calculated based on the awarded scores. Table 1 was adopted for the comprehensive evaluation of the tested machines on the line with the modified McKinsey matrix. Results from two machines were averaged in order to evaluate the whole line. Afterwards, the results were compared with the output obtained for the remaining lines - those that manufacture the food product - and with the other technological lines operated in the company in question. 
Table 1

Modified McKinsey matrix for the comprehensive evaluation of machines on the labelling and packaging line.

\begin{tabular}{|c|c|c|c|c|c|c|c|c|c|}
\hline & \multicolumn{6}{|c|}{ Ranking } & \multirow{3}{*}{ Calculations } \\
\hline $\mathrm{No}$ & 50 & & 0 & 1 & 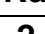 & 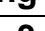 & 1 & & \\
\hline No. & Factor & $\begin{array}{c}\text { Valıdity } \\
\text { in\% }\end{array}$ & 0 & 1 & 2 & 3 & 4 & 5 & \\
\hline 1 & Safety & 25 & & & & & & & \\
\hline 2 & Advancement & 15 & & & & & & & \\
\hline 3 & Cleanliness & 15 & & & & & & & \\
\hline 4 & Completeness & 15 & & & & & & & \\
\hline 5 & $\begin{array}{l}\text { OEE line (min } \\
0.35 ; \max 1)\end{array}$ & 10 & & & & & & & \\
\hline 6 & Maintenance & 10 & & & & & & & \\
\hline 7 & Improvements & 10 & & & & & & & \\
\hline & MIN & 0 & & & & & & & \\
\hline & MAX & 500 & & & & & & & \\
\hline
\end{tabular}

Source: Own study

\section{RESULTS}

\section{The result of advancement evaluation}

Taking into account the assessment of the level of advancement of the examined machines on the labelling and packaging line with the $A B C$ technology method and the 5-point Parker scale, results were obtained which were included in the ParetoLorenzo diagram (Fig. 3).

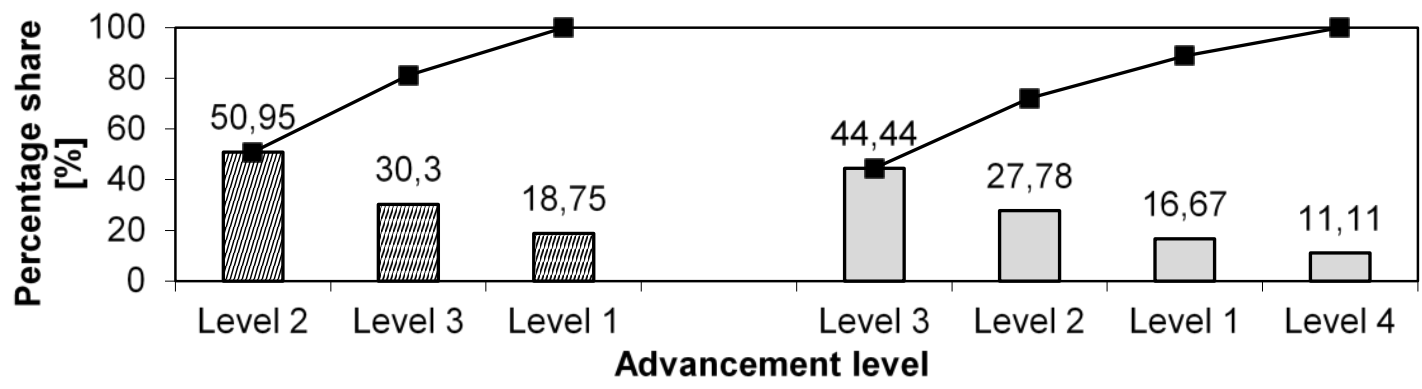

Fig. 1. Pareto-Lorenz diagram for capturing the structure of machine components:

Source: Own study

a) labelling machine, b) packing machine.

Level 2 is dominant when it comes to the labelling machine advancement, which indicates that it is not a modern device. Poor results were noted in the components responsible for feeding the adhesive and applying it on the label before gluing takes place. Numerous technical problems related to the spreading of the glue were observed as well as some difficulties in keeping both the machine and its surroundings clean. Numerous deficiencies in the modernization of the device were demonstrated, including unrenovated paint coatings which pose a threat to the GMP and HACCP standards being adhered to by the examined company.

Level 3 is dominant when it comes to the packaging machine advancement, which ensures its functions to be fulfilled correctly. High scores accounting for level 4 of advancement, were allocated to the control and temperature measurement system adopted in the welding process. Other components are characterized with simple 
structures made of standard materials and with standard technologies of low level of advancement. The most frequently selected rating value from the Parker scale, in the case of both machines, evaluating the technology was rating 2 for the labelling machine and rating 3 for the packaging machine.

The result of the efficiency evaluation

Taking into account the efficiency evaluation regarding the use of machines on the labelling and packaging line with the OEE indicator, the obtained results indicate a relatively low level of efficiency for the last 30 days of operation of the tested line: $D x$ $P \times Q=90.90 \% \times 51.67 \% \times 99.98 \% / 10,000=46.92 \%$. The effective use of operation time of the tested line is low $-46.92 \%$, which means that for $53.08 \%$ of the operation time, machines on the line did not fulfil their functions fully. The "Performance" indicator had the largest share in the final value of the OEE indicator. For the tested line (labelling machine and packaging machine), due to the value of OEE $=46.92 \%$, the rating "1" was awarded on a scale of 1-5.

Result of the safety evaluation

The safety level analysis and evaluation as regards the tested machines brought certain results indicating that the level of work safety on the tested machines is sufficient - rating "3". The result was affected by: identified dangerous situations during on-site observations, confirmed historical data indicating the occurrence of near misses.

The result of the comprehensive evaluation of the machines in the line

The result of adopting the modified McKinsey matrix for the comprehensive evaluation of the machines in the line is presented in Table 2.

Table 2

Evaluation of machines on the labelling and packaging line using the McKinsey matrix

\begin{tabular}{|c|c|c|c|c|c|c|c|c|c|}
\hline & & & & & & & & & \\
\hline & & & & & Rar & ing & & & \\
\hline No. & Factor & $\begin{array}{l}\text { Validity } \\
\text { in\% }\end{array}$ & 0 & 1 & 2 & 3 & 4 & 5 & Calculations \\
\hline 1 & Safety & 25 & & & & OD & & & $\mathrm{O}=75 ; \mathrm{D}=75$ \\
\hline 2 & Advancement & 15 & & & 0 & D & & & $O=30 ; D=45$ \\
\hline 3 & Cleanliness & 15 & & & 0 & D & & & $\mathrm{O}=30 ; \mathrm{D}=45$ \\
\hline 4 & Completeness & 15 & & & D & 0 & & & $\mathrm{O}=45 ; \mathrm{D}=30$ \\
\hline 5 & $\begin{array}{l}\text { OEE line (min } \\
0.35 ; \max 1)\end{array}$ & 10 & & O D & & & & & $O=10 ; D=10$ \\
\hline 6 & Maintenance & 10 & & & 0 & D & & & $O=20 ; D=30$ \\
\hline 7 & Improvements & 10 & D & & 0 & & & & $O=20 ; D=0$ \\
\hline & MIN & 0 & & & & & & & $0=230$; \\
\hline & MAX & 500 & & & & & & & $D=235$ \\
\hline
\end{tabular}

Where: $\mathrm{O}$ - labelling machine, $\mathrm{D}$ - packaging machine

Source: Own study

The obtained ratings for the two tested machines are similar when it comes to their values. They place the tested machines more or less in the middle of the maximum range value. Having averaged the evaluations of the machines tested, the obtained was result of 232.5. The analysis of the tested line comparing it to other lines participating in the manufacturing of the tested product (x6) proved that it is the lowest-rated line. Out of all the evaluated lines, the tested was ranked third from the 
bottom of the list! The average value of all ratings for all lines in the company was 322.41 .

\section{DISCUSSION}

The major intention of the study was to interrelate the results of evaluations of such three factors as: 1. advancement, 2. efficiency, 3. work safety, obtained by various methods in relation to machines included in the labelling and packaging line, to evaluate this line and draw conclusions about its improvement. The obtained results were grasped in the form of the McKinsey matrix, which allowed for a comprehensive assessment of the equipment of the tested line and the line itself. The evaluation was afterwards also employed for comparison and improvement purposes.

The research showed that the tested line is one of the worst-rated lines in the entire company. Such an assessment was due to very poor results in the field of efficiency of use (OEE) and introduced improvements, below-average and average results in terms of advancement, cleanliness, completeness and maintenance of the machines. The safety level was rated as medium. Certain actions should be taken to reduce the failures, any minor down-times and slowdowns of work, which is necessary to reduce the occurrence of near misses.

The main advantages of the study are its versatility and comprehensiveness as well as the possibility of initiating improvement activities. At the same time, the ability to modify the qualitative characteristics (traits) and add them to the list allows the scope of the research to be shaped (broadened) freely.

A limitation related to the use of this method is relatively high labor consumption (preliminary tests are required - ABC technology method, OEE analysis), lack of specific descriptors (discriminants) in relation to additional factors. The correct selection of experts, who should know the machine / line from theirs experience, was recognized as a critical element in the study.

As regards the indicated limitations, it is planned to prepare an auxiliary form with descriptions for values from the 1-5 scale, for the factors which have been subjective so far, in order to objectify them.

\section{CONCLUSION}

The level of work safety, advancement and efficiency of use are the factors that significantly affect the quality of the final product on the labelling and packaging line. Presenting all these factors as a single numeric value was a challenge was faced the context of this paper. Each factor was evaluated individually, and afterwards - based on the obtained ratings and the assumed validity coefficients - a general assessment of the equipment of the tested line was indicated. Thanks to the adoption of a uniform machine evaluation system, it was possible to conduct a comparative assessment of the tested line with other technological lines in the company.

The carried out analyzes and assessments proved that the tested line is one of the worst-rated in the whole company - and this is the consequence of no previous improvement actions, low level of efficiency of use and relatively low level of advancement. Based on the obtained results, it was proposed to undertake improvement actions aimed at increasing the level of the worst-evaluated factors.

In order to carry out a similar study, make sure that you choose the right experts who, with their knowledge and experience, should support you in determining the validity of 
factors. The number, naming and importance of factors can be freely determined depending on the purpose of the study and the expected results.

How else to assess, with a single number, the resultant level of work safety, efficiency of use and advancement of machines / lines while maintaining a uniform evaluation system?

\section{REFERENCES}

Anand, S.R., Nandurkar, K.N., 2012. Optimizing \& Analysing Overall Equipment Effectiveness (OEE) Through Design of Experiments (DOE), Procedia Engineering, Vol. 38, 2973-2980.

Borkowski, S., Selejdak, J., Salomon, S., 2006. Efektywność eksploatacji maszyn i urządzeń, Wydawnictwo Wydziału Zarządzania Politechniki Częstochowskiej, Częstochowa.

Dziuba, Sz. T., Ingaldi, M., Kadłubek M., 2016. Use of Quality Management Tools for Evaluation of the Products' Quality in Global Economy, $16^{\text {th }}$ International Scientific Conference Globalization and Its Socio-Economic Consequences, University of Zilina, Zilina, 425-432.

Ingaldi, M., Dziuba, Sz. T., 2015. Modernity Evaluation of the Machines Used During Production Process of Metal Products, $24^{\text {th }}$ International Conference on Metallurgy and Materials, Tanger, Ostrava, 1908-1914.

Knop, K., 2018. The Impact of Performance Improvement Achieved by the Closing Machine up to the Level of World-Class OEE on the Results of the Production Process, Materials Research Proceedings, Vol. 5, 117-122.

Knop, K., Borkowski, S., 2009. Quality Problems in the Process of Labeling Glass Packages, in: Borkowski S., Novak A. (Eds.), Evaluation of Production Processes, Novosibirsk State Tech. Univ., Novosibirsk.

Krynke, M., Mielczarek, M., 2018. Applications of Linear Programming to Optimize the Cost-Benefit Criterion in Production Processes, $12^{\text {th }}$ International Conference Quality Production Improvement (QPI 2018), Vol. 183.

Kula, P., 2004. Etykietowanie opakowań w procesie produkcyjnym, „Ważenie, dozowanie, pakowanie", 2/2004.

Maszke, A., Dwornicka, R., Ulewicz, R., 2018. Problems in the Implementation of the Lean Concept at a Steel Works - Case Study, MATEC Web Conf. 183, 01014, DOI: 10.1051/matecconf/201818301014.

Mikulová, P., Plura, J., 2018. Comparison of Approaches to Gauge Repeatability and Reproducibility Analysis, MATEC Web Conf. 183, 03015, DOI: 10.1051/matecconf/201818303015.

Muchiri, P., Pintelon, L., 2008. Performance measurement using overall equipment effectiveness (OEE): literature review and practical application discussion, International Journal of Production Research, Vol. 46, Iss.: 13, 3517-3535.

Ulewicz, R., 2016. Quality management system operation in the woodworking industry, in: The Path Forward for Wood Products: A Global Perspective Proceedings of Scientific Papers, 51-56.

Yam, K.L., Takhistov, P.T., Miltz, J., 2005. Intelligent packaging concepts and applications, Journal of Food Science, 70, R1-R10, DOI: 10.1111/j.13652621.2005.tb09052.x. 